\title{
Can allo-SCT with RIC cure ATLL? Long-term survivors with excellent PS and with heterogenous HTLV-1 proviral load level
}

\author{
Naokuni Uike ${ }^{1 *}$, Ryuji Tanosaki ${ }^{2}$, Atae Utsunomiya ${ }^{3}$, Ilseung Choi ${ }^{1}$, Jun Okamura ${ }^{4}$ \\ From 15th International Conference on Human Retroviruses: HTLV and Related Viruses \\ Leuven and Gembloux, Belgium. 5-8 June 2011
}

\section{Background}

Adult T-cell leukemia/lymphoma(ATLL) has so far had a very poor prognosis by chemotherapy. From the longterm observations of our previous clinical trials (NST-1/ NST-2; allogeneic hematopoietic stem cell transplantation with reduced-intensity conditioning regimen (RIC) for ATLL patients), we suspect that RIC strategy might have a possible curative power for ATLL patients (pts).

\section{Objective}

We evaluated the safety and feasibility of allogeneic hematopoietic stem cell transplantation with RIC from matched sibling donors (MSD) for ATLL pts using a conditioning regimen consisting of fludarabine and busulfan. Low-dose antithymocyte globulin was added in the 1st study (NST-1), while it was omitted for the 2nd study (NST-2). We present the results of long-term follow-up of the two trials as well as the longitudinal patterns of changes in HTLV-1 proviral load in survivors.

\section{Patients and methods}

Between Apr, 2001 and Feb, 2006, 30 pts ranged from 50 to 67 years of age were enrolled in NST-1(16 pts) and NST-2 (14 pts). After undergoing the conditioning regimen, they received G-CSF-mobilized peripheral blood (PB) stem cells from HLA-matched sibling donors (MSD). Half of the donors were HTLV-1 carriers. The primary end points in both studies were achievement of complete donor chimerism before day 90, and absence of early transplant-related mortality (TRM) before day100. The HTLV-1 proviral load was estimated using PB samples serially after RIC. HTLV-1 proviral DNA

\footnotetext{
* Correspondence: nuike@nk-cc.go.jp

'Department of Hematology,National Kyushu Cancer Center, Fukuoka, Japan Full list of author information is available at the end of the article
}

was measured by the quantitative PCR amplification of HTLV-1 pX DNA. The detection limit of the HTLV-1 proviral load was 0.5 The overall survival (OS) curve was estimated by the Kaplan-Meier method.

\section{Results}

The results have been already published elsewhere (Okamura, Blood, 2005, Tanosaki, BBMT, 2008, Choi, BMT, 2011). Ten of the 29 evaluable patients have survived for a median of 115 months (range, 85-130 months) after RIC. All of them maintain their good health (Karnofsky PS score ?90\%). The majority of survivors have developed the graft-versus host disease (GVHD) (10/10 pts for acute GVHD and 9/10 pts for chronic GVHD). Overall and progression free survival rates at 5 years for the studies were $36 \%$ (95\% IC, 21 to 51\%) and 31\% (95\% IC, 17 to $45 \%)$, respectively. Serial changes in the HTLV-1 proviral load after RIC in the pts are heterogeneous but can be roughly classified into 3 patterns. In the first pattern, seen in 3 pts, the proviral load became undetectable after RIC and continued to remain so. In the second pattern, seen in 3 pts who had received RIC from HTLV-1 negative donors, the proviral load had become undetectable but returned to detectable levels thereafter. Lastly, in the third pattern, seen in 4 pts who had received the grafts from HTLV-1-carrier donors, the proviral load had remained at the carrier level. All the 10 survivors continue to show complete donor chimera during the observation period regardless of the HTLV-1 proviral load level.

\section{Conclusion}

The long-trem follow-up in our study indicates not only that RIC from MSD is a feasible treatment modality for ATL, but also that one third of the pts may be cured 
with this procedure because all survivors are good for health. As for post-RIC changes in HTLV-1 proviral load in long-term survivors it seems heterogenous, which may be categoryzed into 3 patterns.

\section{Acknowledgements}

(Other coauthors ; T Fukushima, M Harada, T Etoh, Y Saburi, H Kikuchi, M Hidaka, M Matsuoka, M Kannagi, T Yamanaka. Supported by a grant for anticancer project from Ministry of Health, Welfare, and Labor of Japan.)

\section{Author details}

'Department of Hematology,National Kyushu Cancer Center, Fukuoka, Japan.

${ }^{2}$ Stem Cell Transplantation Unit,National Cancer Center Hospital, Tokyo, Japan. ${ }^{3}$ Department of Hematology,Imamura Bun-in Hospital, Kagoshima, Japan. ${ }^{4}$ Institute for Clinical Research, National Kyushu Cancer Center, Fukuoka, Japan.

Published: 6 June 2011 load level. Retrovirology 2011 8(Suppl 1):A33.

\section{Submit your next manuscript to BioMed Central} and take full advantage of:

- Convenient online submission

- Thorough peer review

- No space constraints or color figure charges

- Immediate publication on acceptance

- Inclusion in PubMed, CAS, Scopus and Google Scholar

- Research which is freely available for redistribution

Submit your manuscript at www.biomedcentral.com/submit 